(2) Open Access Full Text Article

\title{
Aggressive digital papillary adenocarcinoma - a rare malignant tumor of the sweat glands: two case reports and a review of the literature
}

This article was published in the following Dove Press journal:

Clinical, Cosmetic and Investigational Dermatology

25 March 2015

Number of times this article has been viewed

\author{
Silke Altmann' \\ Hans-Georg Damert ${ }^{1}$ \\ Stephanie Klausenitz ${ }^{2}$ \\ Manfred Infanger' \\ Armin Kraus' \\ 'Department of Plastic, Aesthetic \\ and Hand Surgery, Otto-von- \\ Guericke-University Magdeburg, \\ ${ }^{2}$ Private Institute for Pathology, \\ Magdeburg, Germany
}

\begin{abstract}
Aggressive digital papillary adenocarcinomas are rare malignant tumors often located on the digits of the hand. Due to lack of pain, slow growth, and an inconspicuous appearance, diagnosis is often missed or delayed. We report two cases and review the present literature to give recommendations for diagnosis and treatment.
\end{abstract}

Keywords: aggressive digital papillary adenocarcinoma, tumor, sweat glands

\section{Introduction}

Sweat gland carcinomas are rare malignant tumors of the skin. ${ }^{1-5}$ One entity is the aggressive digital papillary adenocarcinoma. These tumors are capable of aggressive local invasion resulting in a high recurrence rate, and are characterized by predominantly digital location. As the tumor is slow-growing, painless, and clinically inconspicuous, the diagnosis is often missed or delayed. We report two cases of aggressive digital papillary adenocarcinoma, including clinical course, pathological findings, and therapeutic approach, and review the present literature.

\section{Case report I}

A 52-year-old man presented with a 12-month history of a swelling of the distal phalanx of the right middle finger without prior trauma or infection (Figure 1). The tumor was not palpable because the fingertip was plump and sometimes painful. There was no redness, discoloration, or inflammation of the skin. Sensation, motion, and perfusion were not impaired. X-ray findings showed no bony involvement. Intraoperatively, we observed a cystic brown tumor with a soft consistency (Figure 2). Histologic examination revealed a cystic tubulopapillary epithelial tumor. A computed tomographic scan of the chest, ultrasound of the abdomen, and bone scintigraphy showed no evidence of metastasis. We chose an aggressive surgical approach consisting of amputation of the middle phalanx and regional lymph node dissection. The surgical margins of the finger and the lymph nodes were free of tumor. Ten-year follow-up did not show any recurrence.

\section{Case report 2}

A 54-year-old man presented with a $1 \times 1 \mathrm{~cm}$ solid painless tumor on the dorsal side of the middle phalanx of the right middle finger. The tumor showed slow growth over 14 months. The tumor had been previously resected at another institution under local anesthesia. The histologic report disclosed an aggressive digital 


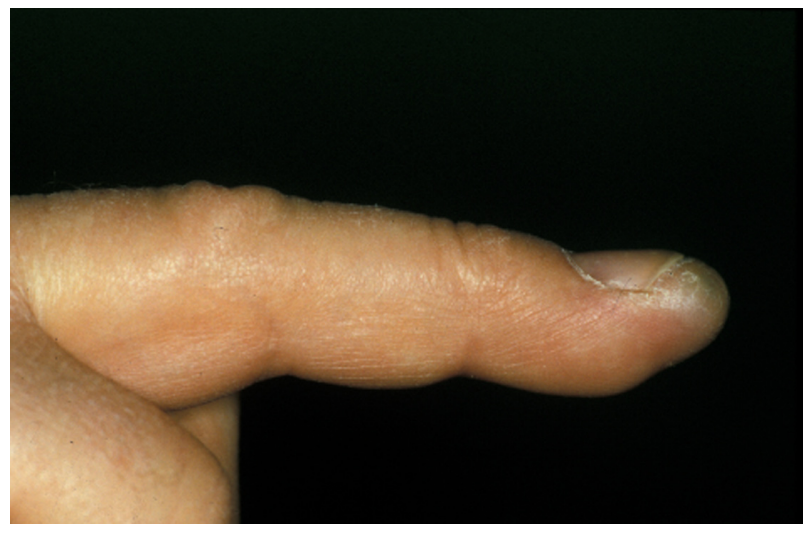

Figure I Swelling of the distal phalanx of the right middle finger without prior trauma or infection.

papillary adenocarcinoma with margins not free of tumor (Figures 3-6). Physical examination at our institution showed a bland scar on the middle dorsal phalanx with full function of the hand. X-ray imaging of the hand, magnetic resonance imaging, and a computed tomographic scan of the chest and abdomen were not suspicious for tumor spread. The patient refused finger amputation. An excision of the scar with adequate safety margins was done once again. There were no tumor cells detected in the histological specimen. The defect was covered with a full-thickness skin graft (Figure 7). The sentinel lymph node was free of tumor. Postoperative wound healing was very good, and function of the right hand was not impaired. Staging procedures, including colonoscopy, bronchoscopy, gastroscopy, and ultrasound of the thyroid gland revealed no further tumor localization. No recurrence was detected at follow-up after 18 months.

\section{Discussion}

Aggressive digital papillary adenocarcinoma is a rare cutaneous malignancy. ${ }^{1-9}$ It was first described in 1984 by Helwig et al, who used the term "eccrine acrospiroma". The term "aggressive digital papillary adenocarcinoma" was

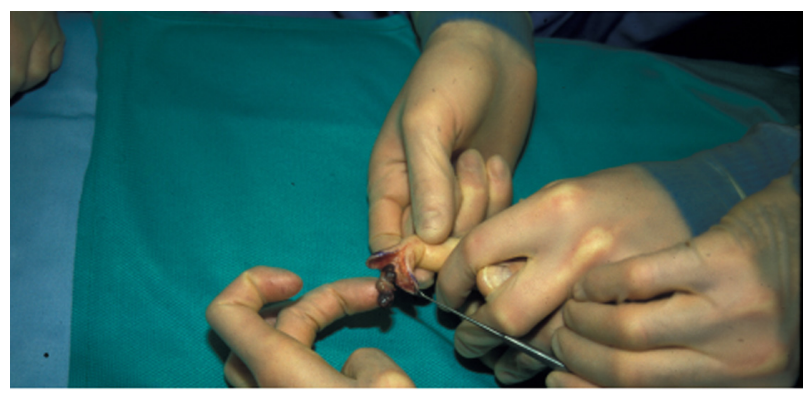

Figure 2 Intraoperative view of a cystic brown tumor with a soft consistency.

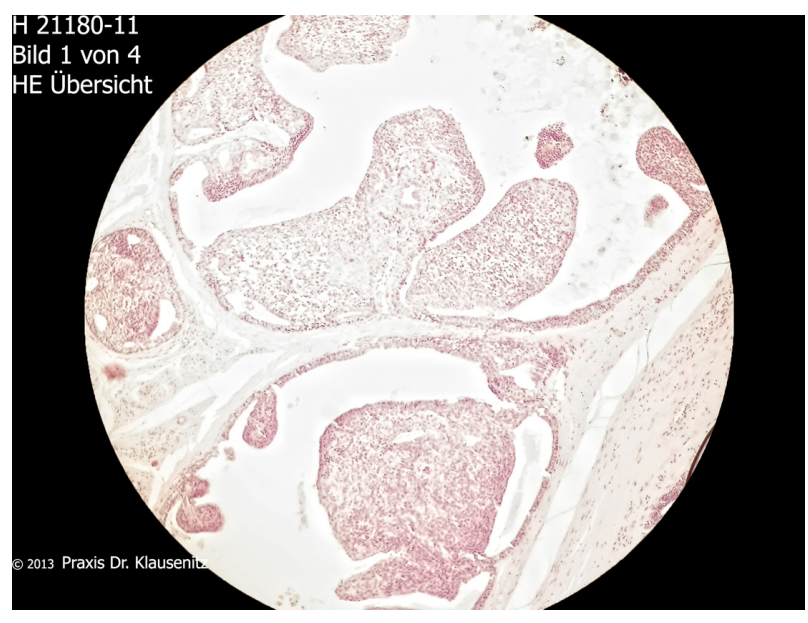

Figure 3 Low-grade papillary eccrine adenocarcinoma with intracystic macropapillary contents.

introduced decades later by Duke et al, ${ }^{2}$ although it is a lowgrade rather than a high-grade malignancy. Histologically, tumor features include a grenz zone, fibrocollagenous stroma, a mixed tubuloalveolar and papillary pattern, and focal squamous metaplasia. ${ }^{10}$ The differential diagnosis comprises apocrine adenocarcinoma, adenoid cystic carcinoma of the sweat glands, and mucinous eccrine carcinoma. Large series published about this entity are rare. There is one initial retrospective clinicopathological study published by Kao et al, which included 57 patients. ${ }^{7}$ The authors reported a local recurrence rate of $47 \%$ and a $41.2 \%$ rate of distant spreading. Patients with metastases died 5-20 years after diagnosis, indicating the low-grade malignancy of the tumor. Authors classified subgroups as aggressive digital papillary adenomas and aggressive digital papillary adenocarcinomas based on histological criteria. Currently, it is recommended

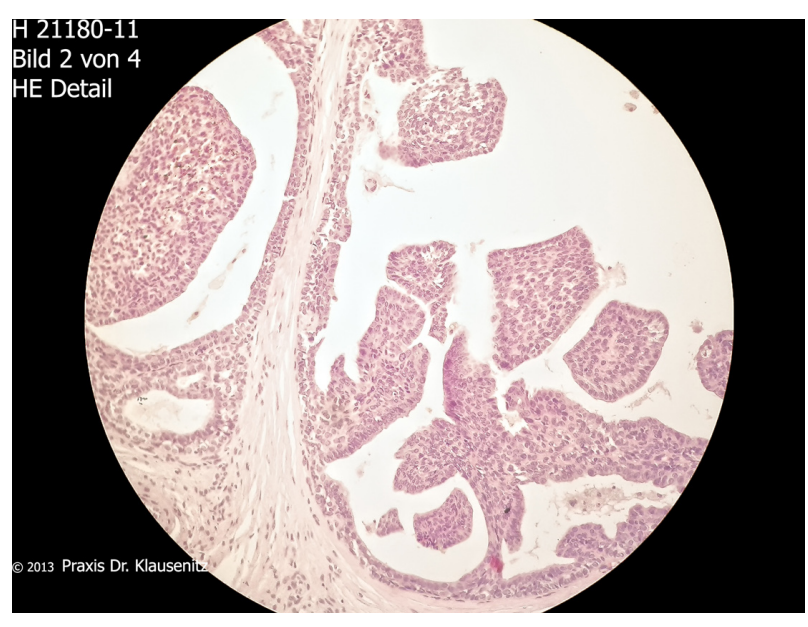

Figure 4 Small and monomorphic nuclei without necrosis. 


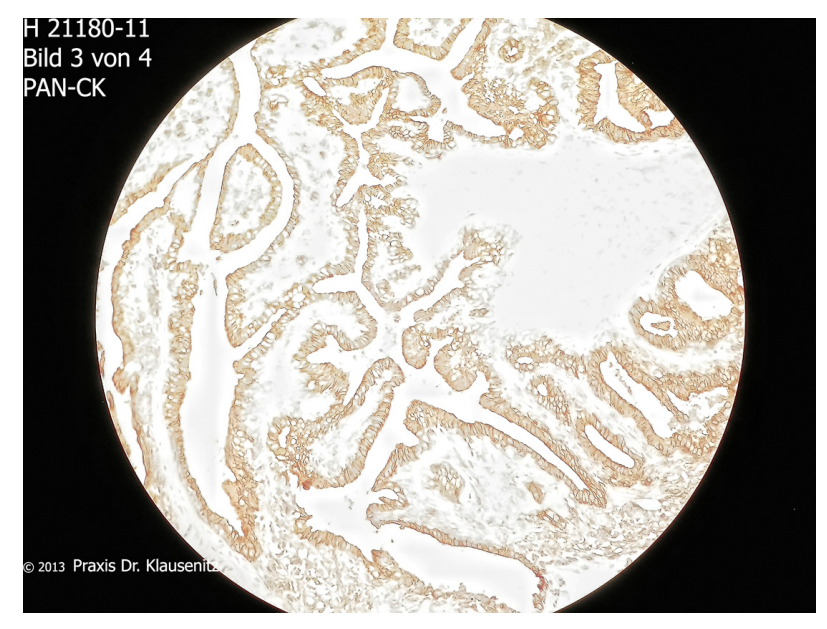

Figure 5 Pan-cytokeratin positive staining in immunocytochemistry.

to avoid the term aggressive digital papillary adenoma, as all such tumors possess metastatic potential. ${ }^{2}$ Other authors report lymph node and lung metastases developing in up to $14 \%$ of cases. ${ }^{6,8}$ There is no effective treatment for widespread disease. Another follow-up study of aggressive digital papillary adenocarcinomas from the same institution was published in 2000 by Duke et al. ${ }^{2}$ Sixty-seven cases were included in this study. These authors found subsequent radical excision to be imperative to prevent local recurrence. In this series, only $5 \%$ recurrence occurred when the tumor was treated with subsequent excision or digital amputation, compared with $50 \%$ recurrence when not so treated. Interestingly, none of the clinical or histological features described above was predictive for local recurrence or metastasis. The findings of a recent study from 2012 that included 31 patients are in accordance with the results described above. ${ }^{11}$ These authors recommended wide excision or amputation as

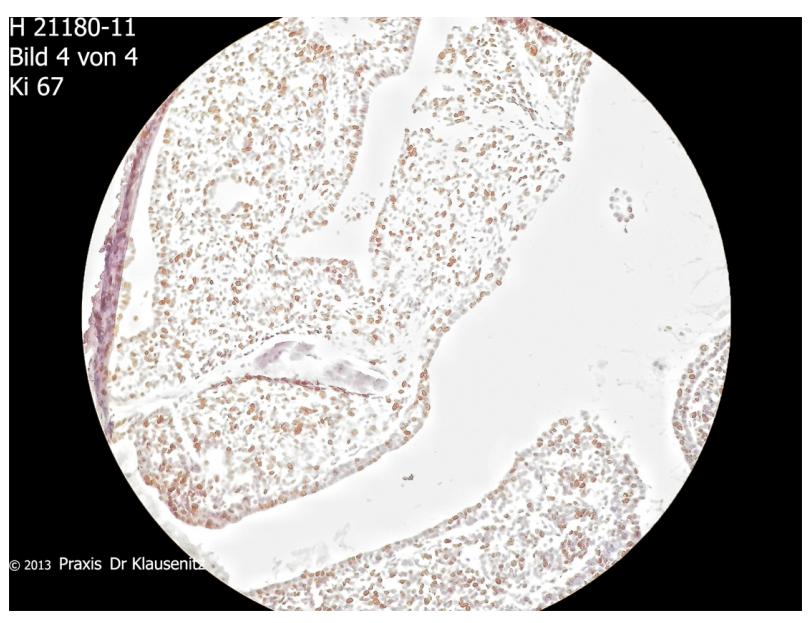

Figure 6 High proliferation activity in areas of solid tumor, Ki67 index 20\%.

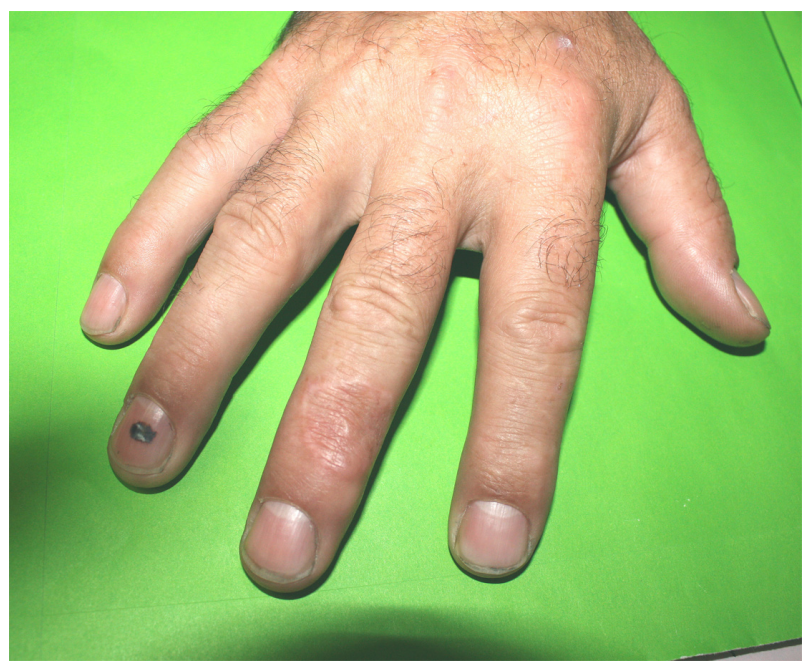

Figure 7 Postoperative view after tumor resection and coverage by full-thickness skin graft.

treatment, and reported a local recurrence rate of $16 \%$ thereafter. The metastasis rate was reported to be $19 \%$, and $16 \%$ of metastases were located in the lung. Concerning the clinical appearance, the lesion often presents as a nonspecific mass in the fingers or toes, which gradually enlarges over years. ${ }^{7,9}$ Dorsal localization, as in our second case, is very uncommon, but should be taken into consideration. The typical age of patients with aggressive digital papillary adenocarcinoma is the fifties to seventies, with a predominance of male over female patients., ${ }^{711}$ The history in both our cases was very similar, ie, a painless tumor with slow growth. The histology of our cases showed partly solid and partly cystic tumor tissue with papillary epithelial proliferation. No recurrence or metastasis has been detected in our patients during follow-up. Due to the slow growth and absence of symptoms, the patient and the physician in charge often trivialize the findings. The tumor can be easily confused with infection, a ganglion, or a cyst, which can lead to wrong or delayed therapy.

In accordance with recommendations given in a previous study, ${ }^{12}$ we propose an exact diagnosis followed by a radical excision of the tumor (excisional biopsy plus subsequent radical excision) and staging of the regional lymph nodes, lung, and abdomen. The benefit of sentinel lymph node biopsy is still controversial. ${ }^{13}$ We recommend a clinical follow-up period of 10 years.

\section{Conclusion}

Digital papillary adenocarcinoma is a rare but life-threatening malignancy, and the diagnosis is easily missed or delayed. 
Physicians in charge should be aware of their potential existence and confirm the diagnosis by biopsy in suspicious cases. In the event of a confirmed diagnosis, excision biopsy should be followed by radical excision and patient follow-up for a period of 10 years.

\section{Disclosure}

No funding was received for the present work. The authors have no financial or other conflicts of interest to disclose.

\section{References}

1. Daigeler A, Fansa H, Tammer M, Schneider W. [Aggressive digital papillary adenocarcinoma - case report]. Handchir Mikrochir Plast Chir. 2002;34(2):137-139. German.

2. Duke WH, Sherrod TT, Lupton GP. Aggressive digital papillary adenocarcinoma (aggressive digital papillary adenoma and adenocarcinoma revisited). Am J Surg Pathol. 2000;24(6):775-784.

3. Frey J, Shimek C, Woodmansee C, et al. Aggressive digital papillary adenocarcinoma: a report of two diseases and review of the literature. J Am Acad Dermatol. 2009;60(2):331-339.

4. Gole GN, Tati SY, Deshpande AK, Gole SG. Aggressive digital papillary adenocarcinoma in a young female - a rare presentation. $J$ Hand Microsurg. 2011;3(1):31-33.
5. Horner CW, Speller A, McBride T, Dias R. Rare digital tumours: two case reports and mini review. Hand Surg. 2012;17(2):267-270.

6. Hsu $\mathrm{HC}$, Ho CY, Chen $\mathrm{CH}$, Yang CH, Hong HS, Chuang YH. Aggressive digital papillary adenocarcinoma: a review. Clin Exp Dermatol. 2010;35(2):113-119.

7. Kao GF, Helwig EB, Graham JH. Aggressive digital papillary adenoma and adenocarcinoma. A clinicopathological study of 57 patients, with histochemical, immunopathological, and ultrastructural observations. J Cutan Pathol. 1987;14(3):129-146.

8. Keramidas EG, Miller G, Revelos K, Kitsanta P, Page RE. Aggressive digital papillary adenoma-adenocarcinoma. Scand J Plast Reconstr Surg Hand Surg. 2006;40(3):189-192.

9. Rutten A, Requena L. [Sweat gland carcinomas of the skin]. Hautarzt. 2008;59(2):151-160. German.

10. Jih DM, Elenitsas R, Vittorio CC, Berkowitz AR, Seykora JT. Aggressive digital papillary adenocarcinoma: a case report and review of the literature. Am J Dermatopathol. 2001;23(2):154-157.

11. Suchak R, Wang WL, Prieto VG, et al. Cutaneous digital papillary adenocarcinoma: a clinicopathologic study of 31 cases of a rare neoplasm with new observations. Am J Surg Pathol. 2012;36(12): 1883-1891.

12. Singla AK, Shearin JC. Aggressive surgical treatment of digital papillary adenocarcinoma. Plast Reconstr Surg. 1997;99(7): 2058-2060.

13. Morita R, Hatta N, Shirasaki F, Hayakawa I, Ohishi N, Takehara K. Lymphatic mapping and sentinel lymph node biopsy for staging of aggressive digital papillary adenocarcinoma. Plast Reconstr Surg. 2006;117(2):710-712.
Clinical, Cosmetic and Investigational Dermatology

\section{Publish your work in this journal}

Clinical, Cosmetic and Investigational Dermatology is an international, peer-reviewed, open access, online journal that focuses on the latest clinical and experimental research in all aspects of skin disease and cosmetic interventions. All areas of dermatology will be covered; contributions will be welcomed from all clinicians and

\section{Dovepress}

basic science researchers globally. This journal is indexed on CAS The manuscript management system is completely online and includes a very quick and fair peer-review system, which is all easy to use. Visit http://www.dovepress.com/testimonials.php to read real quotes from published authors. 